\title{
CONFIGURAÇÃO DISCURSIVA: UMA NOVA PROPOSTA TERMINOLÓGICA PARA COMPILAÇÃO DE TEXTOS FORMAL E TEMATICAMENTE SEMELHANTES
}

Bruna Longo Biasioli ${ }^{1}$

\section{RESUMO}

Ao se conceitualizar o texto, diversas perspectivas podem ser tomadas como base, como a Linguística Textual, a Análise do Discurso, a Semiótica. Dessa forma, cada corrente enxerga, define e analisa o texto sob a visão de seus teóricos e de seus conceitos. Sendo assim, os termos que são dados aos conceitos estabelecidos por cada teoria são, também, particulares, podendo se diferenciar entre elas, ainda que definindo um mesmo objeto. De acordo com o senso comum, o grupo de textos com características formal e tematicamente semelhantes recebe o nome de gênero ou tema, no entanto, propõe-se, com este trabalho, que se trate de uma configuração discursiva, diferenciando o conceito de gênero, segundo Bakhtin (1997), Marcuschi (2002), Fontanille (1999) e Fairclough (2001), e o conceito de tema, segundo Fiorin (1989) e Greimas e Courtés (1979), da noção de configuração discursiva, proposta pela teoria semiótica greimasiana.

Palavras-chave: Semiótica. Configuração discursiva. Gênero.

\section{INTRODUÇÃO}

O conceito de gênero pertence ao campo de estudo da Análise do Discurso e da Linguística Textual. Para ambas as teorias, os gêneros são manifestações discursivas, que têm caráter ideológico. O discurso, assim, é o local das ideologias sociais. A definição do termo "gênero", no Dicionário de Semiótica (GREIMAS e COURTÉS, 1979, p.228), está relacionada ao universo socioletal. Dessa forma, define-se gênero como uma taxionomia que está veiculada aos discursos sociais manifestados pelo texto.

Para a semiótica, no entanto, o sentido de texto encontra-se em seu próprio interior e não em fatores externos à sua composição. Por esse motivo, que será mais detalhadamente explorado nos próximos subitens deste artigo, não se adota o termo "gênero" para se referir ao grupo de textos com características formal e tematicamente semelhantes, pois há, no interior da teoria que será a base das discussões deste 
trabalho, a semiótica, conceito com um sentido preciso, a "configuração discursiva". Esse conceito da teoria semiótica, segundo a proposta deste trabalho, é mais adequado aos propósitos que aqui se estabelecem, pois focaliza elementos textuais que designam o agrupamento de obras com estruturas discursivas semelhantes, em que o texto é o local em que o sentido se constitui, como será visto adiante.

Assim como não se pode afirmar que o grupo de textos com características formal e tematicamente semelhantes deva receber o nome de gênero, não se pode dizer que ele deva ser considerado como tema de tais obras, visto que, para a semiótica greimasiana, a noção de tema é distinta da noção que o senso comum confere a ela.

Este artigo, portanto, propõe mostrar como os termos "gênero" e "tema", utilizados pelo senso comum ao se referir a obras literárias, poemas, filmes com estrutura formal e tematicamente semelhantes, necessitam ser revistos, uma vez que as próprias teorias que os definem têm, para eles, definições diferentes do que se costuma utilizar.

\section{GÊNERO E CONFIGURAÇÃO DISCURSIVA}

Segundo Bakhtin (1997, p.279), "todas as esferas da atividade humana, por mais variadas que sejam, estão sempre relacionadas com a utilização da língua". Essa utilização é realizada pelos enunciados (orais e escritos), que são determinados pelas condições sociais específicas e finalidades de cada uma dessas esferas. Todo enunciado que é composto pelo conteúdo temático, estilo verbal e construção composicional, marcados pela especificidade de uma esfera da comunicação, pode ser denominado gênero discursivo.

Nas palavras do autor (1997, p. 284):

Uma dada função (científica, técnica, ideológica, oficial, cotidiana) e dadas condições, específicas para cada uma das esferas da comunicação verbal, geram um dado gênero, ou seja, um dado tipo de enunciado, relativamente estável do ponto de vista temático, composicional e estilístico. 
Considerando a heterogeneidade de cada uma das esferas sociais, é possível destacar também como heterogêneos os gêneros discursivos, pois sua riqueza e variedade são infinitas, da mesma forma que a variedade virtual da atividade humana é inesgotável. Na organização de cada esfera de atividade humana, são produzidos enunciados que, por sua vez, formam gêneros "relativamente estáveis", isto é, gêneros discursivos que se caracterizam pelo conteúdo, estilo e composição, representando a esfera social na qual são produzidos.

Em outras palavras, é impossível organizar uma tipologia fechada dos gêneros de discurso, dada sua relação constitutiva com as práticas sociais. Os gêneros são compostos por enunciados relativamente estáveis, apresentam categorias semelhantes, mas são maleáveis, mutáveis de acordo com o contexto em que são produzidos. Isso mostra que a definição de gênero está diretamente relacionada a fatores extratextuais.

Ao levantar a questão sobre que tipo de elemento é combinado na constituição dos tipos de discurso, Fairclough, em diálogo com Bakhtin, adota os termos "gênero", "estilo", "registro" e "discurso". Fairclough (2001, p. 161), sugere que esses termos apresentam diferenças entre si e que os gêneros correspondem muito estreitamente aos tipos de prática social. Para esse autor, "o sistema de gêneros que é adotado em uma sociedade particular, em um tempo particular, determina em que combinações e configurações os outros tipos ocorrem".

Fairclough (2001), numa perspectiva bakhtiniana, afirma que um gênero discursivo implica não somente um tipo particular de texto, mas também processos particulares de produção, de distribuição e de consumo de textos. Assim, de acordo com tais autores, o gênero é definido não somente como uma estrutura semelhante de enunciados, mas como um grupo de enunciados que só produzem sentido em determinada esfera social, a qual, por sua vez, interfere na produção de todo e qualquer texto.

Devido à extrema heterogeneidade dos gêneros do discurso, resultado da infinidade de relações sociais que se apresentam na vida humana, Bakhtin optou por dividir os gêneros em dois tipos: gênero primário (simples) e gênero secundário (complexo). A heterogeneidade linguística é o que determina a subdivisão que se faz entre os gêneros. 
Os chamados gêneros primários são aqueles que surgem das situações de comunicação verbal espontâneas, não elaboradas. Pela informalidade e espontaneidade, pode-se dizer que, nos gêneros primários, há um uso mais imediato da linguagem, visto que entre dois interlocutores há uma comunicação instantânea. Essa imediatez da linguagem ocorre nos enunciados da vida cotidiana: linguagem oral, diálogos com a família, reuniões de amigos, etc.

Os gêneros secundários são configurados, normalmente, pela escrita. O gênero funciona como instrumento, uma forma de uso mais elaborada da linguagem para construir uma ação verbal em situações de comunicação mais complexas e relativamente mais evoluídas: artística, cultural, política. Esses gêneros chamados complexos absorvem e modificam os gêneros primários. Os gêneros primários, ao se tornarem componentes dos gêneros secundários, transformam-se dentro destes e adquirem uma característica particular: perdem sua relação imediata com a realidade existente e com a realidade dos enunciados alheios.

Para melhor compreensão do fenômeno de absorção e de modificação dos gêneros primários pelos secundários, Bakhtin (1997) traz como exemplo uma carta ou um diálogo cotidiano. Uma carta ou um fragmento de conversação do dia a dia, quando inseridos em um romance se desvinculam da realidade comunicativa imediata, só conservando seus significados no plano de conteúdo do romance. Ou seja, não se trata mais de atividades verbais do cotidiano, mas sim de uma atividade verbal artística, elaborada e complexa. É importante lembrar que a matéria dos gêneros primário e secundário é a mesma: enunciados verbais, fenômenos de mesma natureza. O que os diferencia é o grau de complexidade e de elaboração em que se apresentam.

Há, também, a definição de gênero literário, que, da mesma forma, não pode ser utilizada para se referir a textos formal e tematicamente semelhantes. A linguagem é o veículo utilizado para se escrever uma obra literária e os gêneros literários são as várias formas de trabalhar a linguagem, de registrar a história, e fazer com que essa linguagem seja um instrumento de conexão entre os diversos textos que se agrupam em um mesmo gênero.

Os gêneros literários são geralmente divididos, desde a Antiguidade, em três grupos: narrativo ou épico (novelas, contos e romances), lírico (hino, soneto e ode) e 
dramático (farsa, tragédia, comédia). Essa divisão partiu dos filósofos da Grécia antiga, com Platão e Aristóteles, quando dedicavam estudos para o questionamento daquilo que representaria o literário e como essa representação seria produzida. Essas três classificações básicas fixadas pela tradição grega englobam várias categorias menores, comumente denominadas subgêneros, como o romance neo-realista, a poesia bucólica e o teatro do absurdo, por exemplo. (MARCUSCHI, 2002).

A definição de gênero pode ser complementada por Greimas e Courtés (1979, p. 228), quando afirmam que:

O gênero designa uma classe de discurso, reconhecível graças a critérios de natureza socioletal. Estes podem provir quer de uma classificação implícita que repousa, nas sociedades de tradição oral, sobre a categorização particular do mundo, quer de uma "teoria dos gêneros" que, para muitas sociedades, se apresenta sob a forma de uma taxionomia explícita, de caráter não científico. Dependente de um relativismo cultural evidente e fundada em postulados ideológicos implícitos, tal teoria nada tem de comum com a tipologia dos discursos que procura constituir-se a partir do reconhecimento de suas propriedades formais específicas. O estudo da teoria dos gêneros, característico de uma cultura (ou de uma área cultural) dada, não tem interesse senão na medida em que pode evidenciar a axiologia subjacente à classificação: ele pode ser comparado à descrição de outras etno e sociotaxionomias.

Isso mostra que, para a semiótica, a definição de gênero não se dá pelo reconhecimento de traços formais e específicos de determinados discursos, mas sim pelo funcionamento que tais discursos têm em relação ao universo socioletal em que estão inseridos. Como, para a semiótica, o extratextual não é levado em consideração ao se depreender o sentido de um texto, conclui-se que o termo "gênero" não se aplica de forma coerente à proposta teórica de que este trabalho se valerá.

Não é comum encontrar bibliografia que mostre estudos semióticos sobre a questão dos gêneros literários e discursivos. Isto é, a semiótica não aborda de maneira incisiva a questão dos gêneros, no entanto, encontra-se no prefácio de Maupassant. $A$ semiótica do texto: exercícios práticos (GREIMAS, 1993) uma breve explanação de Greimas a respeito do assunto. $\mathrm{O}$ autor traça algumas considerações sobre as "teorias de gêneros" sob a perspectiva semiótica, afirmando que, ao se estudar um texto literário, a questão do universo socioletal passa a ser imprescindível, já que universos socioletais literários seriam classificações feitas com base em dados culturais, capazes 
de articular vários discursos que poderiam, ainda, estabelecer novas produções discursivas.

Assim, sob a perspectiva do gênero, os textos de Guy de Maupassant seriam um "discurso realista", dado que o universo socioletal do Realismo faz parte da produção de sentido desses textos, de acordo com a teoria dos gêneros. Entretanto, sob uma perspectiva semiótica, que não se interessa pelo extratextual, os textos de Maupassant seriam produções capazes de significar por si só, independentemente do movimento literário em que eles estão inseridos. Para Greimas (1976), portanto, toda classificação que tenha como base um movimento literário não nasce do texto, mas vem "de fora" dele.

Dessa forma, para Greimas (1976) não existe texto que seja uma realização perfeita de um dado gênero, sendo esse anterior a qualquer manifestação textual. Isso exclui a questão do gênero do campo de pesquisa da semiótica, pois tratar dos gêneros seria o mesmo que tratar de uma construção anterior ao próprio texto.

Assim, para ele, "não somente não existe texto que seja a realização perfeita de um gênero, mas enquanto organização acrônica, o gênero é logicamente anterior a toda manifestação textual" (GREIMAS, 1993, p. 10).

Por outro lado, Fontanille (1999) retoma essa questão, trazendo, sob um olhar semiótico, uma nova perspectiva sobre os gêneros. Para ele, a definição do gênero se estabeleceria na comparação e no reconhecimento de semelhanças (ou diferenças) entre os diversos textos. Ou seja, tudo aquilo que o texto tem de comum com outros textos é certamente o que o coloca sob a classificação de uma gama de gêneros.

É necessário, no entanto, organizar os textos em tipos reconhecíveis, isto é, incluir as obras dentro de uma categoria maior, reconhecível. Assim, a categorização de um gênero realista, tomando o exemplo acima citado, leva em consideração formas de tematização de um universo literário dado, que são reconhecíveis no interior de uma cultura e são extrínsecas ao texto. Já "conto", "romance" ou "carta" são formas de se reconhecer uma organização textual com base, sobretudo, em propriedades formais intrínsecas ao texto.

Em Semiótica e Ciências Sociais (1976), Greimas continua a expor a problemática da definição do gênero. O autor cita duas definições que, segundo ele, 
"[...] parecem igualmente sábias" (GREIMAS, 1976, p. 188). A primeira refere-se a Pierre Maranda e diz que "o conceito de gênero não é absolutamente pertinente para as pesquisas estruturais" (GREIMAS, 1976, p. 188). A segunda definição vem de Georges Dumézil, que afirma ter passado toda a sua vida buscando a diferença entre mito e conto, em vão. Greimas (1976, p. 188) conclui, então, que se trata "de uma confissão de impotência provisória, de uma afirmação da dificuldade - e não da impossibilidade da solução". E acrescenta (1976, p. 188):

É evidente que essas poucas observações conclusivas não podem pretender trazer uma solução para o problema ao mesmo tempo complexo e irritante dos gêneros literários - problema esse difícil de circunscrever.

Ele afirma que é possível partir do postulado de que todas as narrativas, quaisquer que sejam, obedecem a regras de uma gramática narrativa que, sob o formato de textos, produz objetos narrativos. Esses objetos, embora sejam produtos de uma combinatória de regras, não são todos uniformes, mas distinguem-se em classes e subclasses. Assim, se forem denominados "gêneros" esses objetos narrativos que são construídos segundo as formas canônicas, percebe-se que os gêneros, "enquanto últimos termos de uma arborescência de regras restritivas, resultam de uma classificação de caráter hierárquico que compreende, na parte superior, classes de gêneros cada vez mais gerais" (GREIMAS, 1976, p. 189).

O autor confessa que, naquela época, era impossível realizar a classificação dos gêneros; no entanto, é possível, ao menos, esquematizar uma organização provisória dos critérios de classificação. Assim, já que a definição de um gênero só pode ser estabelecida a partir das propriedades manifestadas em uma determinada classe de textos, o primeiro critério de classificação é a presença ou ausência das propriedades narrativas de caráter estrutural.

Outra possibilidade de classificação citada por Greimas é proposta por A. Buttitta, que afirma que um tipo de narrativa pode ser reconhecido e distinguido dos outros por sua organização estrutural canônica: "assim, o mito seria definido por sua circularidade, a situação final reproduzindo termo a termo a situação inicial da narrativa" (GREIMAS, 1976, p. 189). Greimas também aponta outro critério de classificação, quando se considera a manifestação textual em relação não mais à organização 
estrutural que dá conta dela, mas a um ou outro nível estrutural que se encontram no texto; ele exemplifica:

Assim, certos tipos de poesia, certos discursos científicos têm tendência a prescindir da mediação do nível sintático de superfície, manifestando diretamente as estruturas profundas, sintáticas ou semânticas. É à mesma ordem de idéias, ao mesmo tipo de subcritérios que se pode submeter, provavelmente, as definições da fábula literária ou da máxima. (GREIMAS, 1976, p. 190).

Percebe-se, portanto, que a quantidade e a pertinência dos critérios de classificação dependem, certamente, da quantidade e, sobretudo, da pertinência dos níveis de análise. Assim, o reconhecimento de um nível de manifestação figurativa, diferente do nível em que se situam as estruturas narrativas de superfície e que compreende, entre outras, a análise dos motivos e das isotopias semânticas, fornece novos critérios para uma tipologia dos gêneros: a utilização de certos tipos de motivos com exclusão de outros e as preferências marcadas por certas isotopias.

É nesse nível da figuração, por exemplo, que se pode situar a distinção estabelecida por Dumézil entre o mito e o conto: "o mito caracteriza-se pela manifestação figurativa dos actantes da sintaxe narrativa, sob a forma de atorespersonagens; o conto, pelo contrário, prefere manifestá-los sob a forma de objetos mágicos". E ainda afirma que "as mesmas distinções entre os personagens 'reais' e 'fictícios', presentificados ou acrônicos, poderiam dar conta, segundo Alan Dundes, das diferenças entre mitos, contos e lendas" (GREIMAS, 1976, p. 190).

Outro nível que parece também poder fornecer critérios de reconhecimento e de classificação dos gêneros é o estilístico. Um exemplo que podemos citar é a importância que Mihai Pop atribui às fórmulas iniciais que servem como marcas de gêneros: a expressão "folha verde", por exemplo, anuncia o início da balada rumena, e enunciar o gênero é uma das funções que lhe cabem.

Percebe-se, portanto, que uma tipologia dos gêneros poderia fundar-se não sobre o reconhecimento das propriedades estruturais das narrativas, mas sobre as definições já existentes. Cada cultura possui, assim, sua própria tipologia dos gêneros; dessa forma, o que se poderia eventualmente construir seria uma tipologia das tipologias, e não uma tipologia dos gêneros, uma tipologia cultural, então, "que não 
seria isomorfa como a tipologia estrutural de que falamos anteriormente" (GREIMAS, 1976, p. 191).

A definição, bem como a descrição, não constitui um objeto fechado em si, que se basta. Sabe-se, desde Saussure, que as significações se manifestam como diferenças. A definição, neste aspecto, só é possível na medida em que é tipológica.

Conclui-se, então, que a definição que só se refira a um gênero particular não pode ser considerada pertinente. A definição, assim compreendida, identifica-se com o universo semântico estudado; seus limites são os do próprio projeto científico. Isso não quer dizer que não seja possível arriscar definições provisórias, procurando reunir em um corpus um certo número de "gêneros" empíricos, como os gêneros menores, para reconhecer, assim, propriedades específicas e diferenciadoras.

Greimas termina sua obra afirmando (GREIMAS, 1976, p. 193):

Na medida em que os critérios distintivos dos gêneros emergem ao mesmo
tempo que os níveis ou os campos autônomos de análise que conseguimos
reconhecer, pode-se dizer que os progressos da análise semiótica no seu
conjunto aproximam-nos ao mesmo tempo da elaboração da tipologia dos
gêneros.

Fiorin, em 1990, publicou um artigo na revista Significação. Revista Brasileira de Semiótica, intitulado "Sobre a Tipologia dos Discursos", em que explicitou a problemática dos gêneros. Diz o autor que as diferentes culturas sempre procuraram estabelecer tipologias discursivas e que o estabelecimento dessas tipologias teve, na maioria das vezes, uma finalidade prescritiva. Por exemplo, a poética sânscrita do período clássico é totalmente codificada, e nela cada gênero é constituído por regras às quais todo escritor deveria obedecer.

Assim, é possível distinguir os textos (de acordo com as regras dos gêneros) dos não textos (em desacordo com as regras). Um exemplo que se pode citar é o da tragédia, em que deve ser obedecida a lei das três unidades (espaço, tempo e ação). Caso haja a infringência a essa norma, o texto fica descaracterizado como pertencente ao gênero trágico.

O que não se pode negar é que as modernas teorias do discurso devem tratar do problema dos gêneros, porque não se pode admitir a tese de que "cada discurso seja único e irrepetível" (FIORIN, 1990, p. 91). Segundo o autor, "a questão da tipologia 
discursiva traz duas ordens distintas de problemas: a dos critérios de classificação dos discursos e a dos gêneros" (FIORIN, 1990, p. 91).

Os discursos podem ser classificados a partir de vários critérios estabelecidos a partir dos mecanismos de produção do sentido.

Por um lado, o gênero é um objeto construído por uma abstração generalizante. Os textos são objetos empíricos, representantes impuros deste ou daquele gênero. Tal texto tem tais e tais características de um gênero, mas não tem outras, e assim por diante. Por outro, o gênero não depende de apenas um dos tipos acima sugeridos, mas constitui uma constelação de propriedades específicas, os tipologemas. (FIORIN, 1990, p. 97).

Segundo Fiorin (1990, p. 97), as tipologias elaboradas até hoje não são finas o suficiente para apreender os vários tipos de discursos que circulam em uma dada formação social, porque foram estabelecidas com base em um único parâmetro.

Um exemplo que se pode citar é que o medo é um dos traços que caracteriza o discurso de terror. Ora, mas o medo também está presente em narrativas de suspense, de literatura fantástica, entre outras. Assim, não é possível caracterizar um gênero por apenas um traço recorrente nas narrativas, pois esse mesmo traço pode estar presente em outras produções de sentido também. Isso é ainda mais claro quando esse traço recorrente diz respeito ao efeito de sentido provocado pelo texto, pois diferentes textos podem provocar efeitos de sentido semelhantes, o que impede a possibilidade de classificar um gênero por apenas um traço recorrente em todos eles.

Seguindo a linha de pensamento de Greimas, Fiorin também considera que a "constelação tipológica dos gêneros é social. Varia de época para época. O que numa época era considerado discurso científico pode não ser mais classificado assim" (FIORIN, 1990, p. 97). Dessa forma, os critérios de classificação pertencem à natureza da linguagem. O autor ainda complementa: "Os gêneros dependem de fatores sociais, isto é, dos efeitos de sentido valorizados num certo domínio por uma dada formação social" (FIORIN, 1990, p. 97).

A partir da perspectiva da teoria dos gêneros e das esferas sociais de Bakhtin, já aqui citadas, Fiorin afirma que uma tipologia baseada nos tipos do discurso não pretende constituir uma norma, mas, pelo contrário, quer mostrar quais mecanismos 
geram os diferentes tipos de discursos sociais, como o científico, o político, o religioso, etc.

Assim, é notório o fato de que a definição dos gêneros ainda é problemática para as teorias do discurso, inclusive para a semiótica. Isso constitui um motivo a mais pelo qual se justifica a escolha pelo termo "configuração discursiva" ao agruparmos textos formal e tematicamente semelhantes.

De acordo com os autores e teorias aqui mencionados, o gênero é algo heterogêneo, maleável e relacionado diretamente às condições contextuais de produção e de circulação dos diversos discursos na sociedade. Dessa forma, o termo "configuração discursiva", que abrange somente as características estruturais capazes de render determinado efeito de sentido em um texto, se torna mais adequado a este trabalho, que tem como base uma teoria que prevê que o sentido do texto deve ser depreendido de sua organização interna.

\subsection{Tema e configuração discursiva}

Assim como não se pode afirmar que o terror seja um gênero literário, não se pode dizer que ele deva ser considerado tema de obras literárias, visto que, para a semiótica greimasiana, a noção de tema é distinta da noção que o senso comum confere a ela. A semiótica, segundo Fiorin (1989, p. 73), considera o tema um "investimento semântico, de natureza conceptual, que não remete ao mundo natural, tais como elegância, orgulhoso, raciocinar".

Diferentes textos podem tratar do mesmo "tema", porém de maneira diferente. Esse "tema" amplo, que aparece em vários discursos (o amor, a morte, a infância, a partida, o exílio, etc.) constitui não propriamente um tema, mas uma configuração discursiva. E, se forem abordados de maneiras diferentes, os temas não poderiam ser classificados dentro de uma mesma configuração discursiva.

Fiorin (1989, p. 76) afirma que: "[...] a depreensão da configuração discursiva só é possível a partir do confronto de vários discursos". Isto é, o agrupamento de determinadas obras em uma mesma denominação só pode ser feita após serem analisados traços discursivos semelhantes entre essas obras, ou seja, é preciso que 
seus discursos sejam configurados de formas semelhantes para que provoquem determinado efeito de sentido.

A definição de configuração discursiva, de acordo com a semiótica, é dada da seguinte forma (GREIMAS e COURTÉS, 1979, p. 87):

Numa primeira aproximação, as configurações discursivas aparecem como espécies de micronarrativas que têm uma organização sintático-semântica autônoma e são suscetíveis de se integrarem em unidades discursivas mais amplas, adquirindo então significações funcionais correspondentes ao dispositivo de conjunto.

Para exemplificar, pode-se dizer que o tema da morte pode ter diferentes configurações, como um assassinato, um suicídio ou uma doença. Ora, a maneira de abordagem desse tema pode ser diferente: um assassinato pode ser analisado sob o ponto de vista de uma solução para algum problema (em narrativas de suspense, por exemplo), mantendo um valor eufórico, enquanto em outra narrativa, ele pode ser visto como algo imoral, ilegal, mantendo um valor disfórico. Assim, percebe-se que o tema da morte pode ser transformado em texto de diferentes formas.

O tema, portanto, segundo a teoria semiótica, é a maneira como determinada configuração discursiva é manifestada em alguns textos e, sendo assim, os temas podem ser vários, dentro de uma mesma configuração discursiva. Utilizando o exemplo já aqui citado, o terror, pode-se dizer que ele pode ser manifestado por vários temas, figurativizados, por exemplo, pelas seguintes ações: uma jovem que morreu e volta para se vingar, mistérios de aparelhos eletrônicos que ligam sozinhos em uma casa, um castelo mal assombrado por uma família que habitava o local, etc.

Enfim, percebe-se que a configuração discursiva constitui a maneira por meio da qual determinados textos (com alguns traços semelhantes) podem ser agrupados sob uma mesma denominação, pois seus discursos se configuram de modo a provocar o mesmo efeito de sentido, como do terror ou do suspense, por exemplo. Isso permite que se afirme que a noção de configuração discursiva é distinta da noção de tema proposta pela teoria semiótica. 


\section{CONCLUSÃO}

Como explicitado no corpo deste artigo, não se pode chamar de gênero, literário ou discursivo, o conjunto de obras temática e formalmente semelhantes, da mesma forma que não se pode dizer que ele seja considerado tema de obras literárias, visto que, para a semiótica greimasiana, a noção de tema é distinta da noção que o senso comum confere a esse termo.

De acordo com Fiorin (1989), é preciso que certos discursos sejam configurados de formas semelhantes para que provoquem determinado efeito de sentido. Em outras palavras, a reunião de determinadas obras em uma mesma denominação, como o terror, o suspense, a autoajuda, só pode ser feita após serem analisados traços discursivos semelhantes entre elas. A esse grupo de obras, a semiótica propõe o termo configuração discursiva, aqui também empregado.

De acordo com o que já foi discutido neste artigo, segundo Bakhtin (1997), Marcuschi (2002), Fontanille (1999) e Fairclough (2001), um gênero discursivo implica não somente um tipo particular de texto, mas também processos particulares de produção, de distribuição e de consumo de textos. Em outras palavras, de acordo com tais autores, o gênero é definido não apenas como uma estrutura semelhante de enunciados, mas como um grupo de enunciados que só produzem sentido em determinada esfera social, como a religiosa, a jornalística, por exemplo, a qual, por sua vez, interfere na produção de todo e qualquer texto.

Dessa forma, percebe-se que o conceito de gênero, que é estudado pelo rol teórico da Análise do Discurso, está relacionado ao contexto de produção dos diversos enunciados que circulam socialmente, ou seja, ao extratextual.

Da mesma forma, para Greimas e para os diferentes semioticistas de seu grupo, em cujas obras este trabalho se apoia, não existe texto que seja uma realização perfeita de um dado gênero, sendo esse anterior a qualquer manifestação textual. Isso exclui a questão do gênero do campo de pesquisa da semiótica, pois tratar dos gêneros seria o mesmo que tratar de uma construção anterior ao próprio texto.

Na obra Semiótica e Ciências Sociais (1976), Greimas propõe que todas as narrativas obedecem a regras de uma gramática narrativa que, sob o formato de textos, 
produz objetos narrativos. Esses objetos, embora sejam produtos de uma combinatória de regras, não são todos uniformes, mas se distinguem em classes e subclasses. Assim, se forem denominados "gêneros" esses objetos narrativos que são construídos segundo as formas canônicas, percebe-se que os gêneros resultam de uma classificação hierárquica que compreende classes de gêneros mais gerais.

Assim, observa-se que a definição dos gêneros ainda é problemática para as teorias do discurso, inclusive para a semiótica. Isso constitui um motivo a mais pelo qual se justifica a escolha pelo termo "configuração discursiva" ao serem agrupadas obras temática e formalmente semelhantes.

A noção de gênero literário também não dá conta da classificação das obras de agrupamentos discursivos semelhantes, pois tal conceito se refere à estruturação de obras em categorias maiores que uma simples tendência a determinado percurso temático.

Conclui-se, assim, que o gênero está relacionado diretamente às condições contextuais de produção e de circulação dos diversos discursos na sociedade. Dessa forma, o termo "configuração discursiva", que abrange somente as características estruturais capazes de render determinado efeito de sentido em um texto, torna-se mais adequado a este trabalho, que tem como base uma teoria que prevê que o texto é um objeto que produz significados por si só.

Segundo Greimas e Courtès (1979), a configuração discursiva constitui a maneira por meio da qual determinados textos, com alguns traços semelhantes, podem ser agrupados sob uma mesma denominação, pois seus discursos se configuram de modo a provocar o mesmo efeito de sentido, como do terror ou do suspense, por exemplo. $E$ tal efeito, presente em todas as obras de determinado agrupamento, só é possível pelas construções temática e formal semelhantes entre si.

\section{NOTAS}

${ }^{1}$ Doutora em Linguística e Língua Portuguesa pela UNESP - Universidade Estadual Paulista (FCL Araraquara). Professora na Uniara - Centro Universitário de Araraquara. 


\title{
DISCURSIVE CONFIGURATION: A NEW TERMINOLOGICAL PROPOSAL FOR COMPILATION OF FORMAL AND THEMATICALLY SIMILAR TEXTS
}

\begin{abstract}
By conceptualizing text, several perspectives can be taken as the basis, such as Textual Linguistics, Discourse Analysis, Semiotics. Thus, each chain sees, defines and analyzes the text under the vision of its theorists and their concepts. So, the terms that are given to the concepts established by each theory are also private and can differentiate between them, even though defining the same object. According to common sense, the group of texts with similar formal and thematically characteristics receives the name of gender or theme, however, it is proposed, with this paper, that it is a discursive configuration, differentiating the concept of gender, according to Bakhtin (1997), Marcuschi (2002), Fontanille (1999) and Fairclough (2001), and the concept of theme, according to Fiorin (1989) and Greimas and Courtés (1979), of the notion of discursive configuration, proposed by Greimas semiotic theory.
\end{abstract}

Keywords: Semiotics. Discursive configuration. Gender.

\section{REFERÊNCIAS}

BAKHTIN, Mikhail. Estética da criação verbal. Trad. Maria Emsantina Galvão Pereira. 3. ed. São Paulo: Martins Fontes, 1997.

FAIRCLOUGH, Norman. Discurso e mudança social. Trad. Izabel Magalhães et al. Brasília: Editora [da] Universidade de Brasília, 2001.

FIORIN, José Luiz. Elementos de análise do discurso. São Paulo: Contexto/EDUSP, 1989.

. As astúcias da enunciação. São Paulo: Ática, 1990.

FONTANILLE, Jacques. Véridiction. Sémiotique et littérature. Paris: PUF, 1999.

. In: GREIMAS, A. J; COURTÉS, J. Sémiotique: dictionnaire raisonné de la théorie du langage II. Paris: Classiques Hachette, 1986.

GREIMAS, Algirdas Julius. Semiótica e ciências sociais. Trad. Álvaro Lorencini e Sandra Nitini. São Paulo: Cultrix, 1976. 
. Du sens: essais sémiotiques. Paris: Du Seuil, 1993.

- Maupassant: a semiótica do texto: exercícios práticos. . Trad. Teresinha

Michels e Carmen Gerlach. Florianópolis: Editora [da] UFSC, 1993.

GREIMAS, A. J; COURTÉS, J. Dicionário de semiótica. Trad. Alceu Dias Lima et al. São Paulo: Cultrix, 1979.

MARCUSCHI, L. A. Gêneros textuais e ensino. Rio de Janeiro: Lucerna, 2002. 